\title{
Untersuchungen über das Vorkommen von proteolytischen Enzymen im Thierkörper. Von
}

S. G. Hedin und S. Rowland.

(Der Redaction zugegangen am 14. Mai 1901.)

Vor kurzer Zeit haben wir über ein proteolytisches Enzym in der Milz berichtet, das sich dadurch auszeichnet, dass seine Einwirkung auf Eiweissstoffe in saurer Lösung sehr stark ist, während dieselbe in neutraler und besonders in alkalischer Lösung schwach ist oder sich sogar mit der angewandten Methode nicht nachweisen lässt. ${ }^{1}$ ) Seitdem haben wir Gelegenheit gefunden, unsere Untersuchungen auch auf andere Organe auszudehnen. Die Untersuchungen wurden wie bei den Milzversuchen mit Presssaft von den Organen oder Geweben ausgeführt. Im Folgenden wird für jeden Versuch zunächst die Anzahl Cubikcentimeter 1/10 n-Säure angegeben, welche der ganzen Stickstoffmenge von $5 \mathrm{ccm}$. Saft entspricht; ${ }^{2}$ ) in dèr Tabelle wird dann der durch Gerbsäure nicht fällbare Antheil dieser Stickstoffmenge vor und nach der Digestion - auch in Cubikcentimetern ${ }^{1 / 10}$ n-Säure ausgedrückt - aufgenommen. ${ }^{3}$ ) Wie bei den Milzversuchen wurde die Untersuchung vorgenommen:

1) in mit Essigsäure (zu 0,25\%) oder einer anderen Säure versetztem Saft,

2) in dem Presssaft ohne irgend eine Zugabe (schwach saurer Lösung),

3) in neutraler und

4) alkalischer Lösung.

Die Digestion wurde bei Körpertemperatur vorgenommen, in Gegenwart von Toluol, zur Verhinderung von Bakterienwirkung.

Bei den ersten Versuchen wurde mit Natriumcarbonat neutralisirt und alkalisch gemacht. Da es sich aber heraus-

1) Diese Zeitschrift, Bd. XXXII, S. 341.

2) Die Bestimmung wurde nach $\mathrm{Kjeldahl}$ ausgeführt.

3) Bekanntlich fällt die Gerbsäure, wenn in Ueberschuss vorhanden, weder Pepton noch die Endprodukte der Eiweissverdauung (Hexonbasen und Monamidosäuren). 
stellte, dass in gewissen Fällen, z. B. bei dem Muskelsaft, die Reaction des Saftes während der Digestion sich änderte, so dass die neutralisirte oder sogar die alkalisirte Lösung in 16 Stunden schwach sauer wurde, haben wir bei allen späteren Versuchen für die Herstellung der neutralen und alkalischen Reaction einen Ueberschuss von Calciumcarbonat resp. Magnesiumoxyd gebraucht. Dabei fragt es sich aber, ob das Alkalisiren mit Magnesia auf die Digestion den gleichen Einfluss ausübt, wie das Alkalisiren mit Natriumcarbonat. Dass kein wesentlicher Unterschied vorhanden ist, haben wir an Milzsaft sowie an Pankreassaft nachweisen können. In dem Milzsaft wird die Digestion des Eiweisses durch die Gegenwart sowohl von Magnesiumoxyd, wie von Natriumcarbonat in hohem Grade erschwert, während beide die Digestion des Pankreassafts erleichtern. Da die Einwirkung des Natriumcarbonats in diesen Fällen hinreichend bewiesen wird durch unsere letzte Mittheilung, brauchen wir hier nur Beweise für die Einwirkung von Magnesia darzulegen. Bei der Untersuchung eines Milzsaftes vom Rind fanden wir für die durch Gerbsäure nicht fällbare Stickstoffmenge folgende Zahlen (in Cubikcentimetern 1/10 n-Säure ausgedrückt):

\begin{tabular}{|c|c|c|}
\hline & $\begin{array}{l}\text { Nach } \\
16 \text { Stunden }\end{array}$ & $\begin{array}{l}\text { Nach } \\
60 \text { Stunden }\end{array}$ \\
\hline Mit Essigsäure $(0,25 \%)$ : . . . . . . . & 12,3 & 12,8 \\
\hline Mit $\mathrm{MgO}$. . . . . . . . . . . & 3,3 & 3,6 \\
\hline
\end{tabular}

Pankreaspresssaft vom Rind ergab folgende Resultate: Gesammtstickstoff 54,7 .

\begin{tabular}{|c|c|c|}
\hline & $\begin{array}{c}\text { Nach } \\
\text { 16 Stunden }\end{array}$ & $\begin{array}{c}\text { Nach } \\
40 \text { Stunden }\end{array}$ \\
\hline Mit Essigsäure . . . . . . . . . & 37,3 & 47,1 \\
\hline Ohne Zugabe . . . . . . . . & 41,1 & 49 \\
\hline Mit $\mathrm{CaCO}_{3} \ldots \ldots \ldots$ & 42,6 & 50 \\
\hline Mit $\mathrm{MgO} \ldots \ldots \ldots$ & 49,6 & 52 \\
\hline
\end{tabular}


Wir gehen jetzt zu den eigentlichen Versuchen über.

Milz.

In unserer letzten Mittheilung haben wir über Versuchè mit Milz von Rind, Pferd, Schwein und Schaf berichtet. Dazu können wir jetzt einen Versuch mit Hundemilz fügen. Obwohl uns drei Hundemilzen zur Verfügung standen, konnten wir nicht mehr als $20 \mathrm{ccm}$. Milzsaft darstellen; für den Versuch wurde diese Menge mit dem gleichen Volumen Wasser verdünnt. Reaction sauer. Gesammtstickstoff 24,1 .

\begin{tabular}{|c|c|c|}
\hline & $\begin{array}{l}\text { Vor der } \\
\text { Digestion }\end{array}$ & $\begin{array}{l}\text { Nach } \\
\text { 40 }\end{array}$ \\
\hline Mit Essigsäure $(0,25 \%) \ldots \ldots$ & 5,8 & 19,6 \\
\hline Mit $\mathrm{MgO} \ldots \ldots \ldots \ldots$ & - & 6,7 \\
\hline
\end{tabular}

$11 \mathrm{ccm}$. Saft wurden mit $2 \mathrm{~g}$ feuchtem Fibrin und Essigsäure (zu 0,25\%) versetzt. Nach 12 Stunden war das Fibrin aufgelöst und das Volumen der ganzen Lösung $=13 \mathrm{ccm}$. Nach 40 Stunden wurde analysirt. Die durch Gerbsäure nicht fällbare Stickstoffmenge, für das ursprüngliche Saftvolumen umgerechnet; entsprach 25,6 ccm: Säure. Die Kontrollprobe ohne Fibrin ergab 19,6 (siehe die Tabelle). Die Hundemilz verhält sich folglich wie die Milz der übrigen untersuchten Thierarten.

\section{Lymphdrüsen.}

Für die Versuche mit Lymphdrüsen haben wir nur Mesenterialdrüsen von Kälbern gebraucht.

Versuch 1.

Gesammtstickstoff 34 .

\begin{tabular}{|c|c|c|c|c|}
\hline & $\begin{array}{l}\text { Vor der } \\
\text { Digestion }\end{array}$ & $\begin{array}{l}\text { Nach } \\
\text { 12 Stunden }\end{array}$ & \begin{tabular}{|c|}
\multicolumn{2}{|}{ Nach } \\
36 Stunden
\end{tabular} & $\begin{array}{c}\text { Nach } \\
60 \text { Stunden }\end{array}$ \\
\hline Mit Essigsäure $(0,25 \%) \quad \therefore$ & 6 & 21 & $27-$ & 27,6 \\
\hline Ohne Zusatz . . . . . & - & - & 7,8 & $-\ldots$ \\
\hline Mit $\mathrm{MgO}$. . . . . . . & - & 6 & 7,2 & - \\
\hline
\end{tabular}


Eine gekochte und mit Essigsäure 36 Stunden digerirte Probe ergab die Zahl 7,2. $2 \mathrm{~g}$ feuchtes Fibrin wurde von $10 \mathrm{ccm}$. des essigsauren Safts in 12 Stunden aufgelöst. Nach 36 Stunden wurde der durch Gerbsäure nicht fällbare, für das ursprüngliche Volumen umgerechnete, Stickstoff $38 \mathrm{ccm}$. Säure entsprechend, gefunden. Kontrollprobe ohne Fibrin ergab 27 (siehe Tabelle).

Versuch 2.

Gesammtstickstoff 28,55.

\begin{tabular}{|c|c|c|c|c|}
\hline & $\begin{array}{l}\text { Vor der } \\
\text { Digestion }\end{array}$ & $\begin{array}{l}\text { Nach } \\
12 \text { Stunden }\end{array}$ & $\begin{array}{l}\text { Nach } \\
36 \text { Stunden }\end{array}$ & $\begin{array}{l}\text { Nach } \\
\text { 84 Stunden }\end{array}$ \\
\hline Mit Essigsäure $(0,25 \%) \quad \ldots$ & 4,3 & 21,4 & 22,7 & 24,4 \\
\hline Mit Milchsäure $(0,25 \%) \quad \ldots$ & - & 14,5 & 17,4 & - \\
\hline Mit $\mathrm{HCl}(0,1 \%)$. . . . & - & 12,4 & 15,5 & - \\
\hline Mit $\mathrm{CaCO}_{3} \cdot$. . . . . . & - & 7,2 & 9,8 & - \\
\hline Mit $\mathrm{Na}_{2} \mathrm{CO}_{3}(0,2 \%) \ldots$ & - & 5,9 & 8,7 & - \\
\hline
\end{tabular}

Mit Fibrin und Essigsäure wie im vorigen Versuche wurde nach 84 Stunden, für das ursprüngliche Volumen umgerechnet, die Ziffer 46 erhalten. Kontrollprobe ohne Fibrin 24,4. In eine Probe mit MgO eingebracht, wurde das Fibrin nicht aufgelöst, sondern bildete mit dem Saft eine ziemlich feste Masse, die nicht analysirt werden konnte.

In diesem Versuch wurden zwei Proben mit Phosphorwolframsäure gefällt und der Stickstoffgehalt des Filtrats ermittelt. Vor der Digestion wurde die Zahl 1,6 erhalten und nach 84 Stunden mit Essigsäure die Ziffer 13.

\section{Nieren.}

Versuch 1 (Kalbsnieren).

Gesammtstickstoff 44,9 .

\begin{tabular}{l|c|c|c|c}
\hline & $\begin{array}{c}\text { Vor der } \\
\text { Digestion }\end{array}$ & $\begin{array}{c}\text { Nach } \\
\text { 12 Stunden }\end{array}$ & $\begin{array}{c}\text { Nach } \\
\text { 36 Stunden }\end{array}$ & $\begin{array}{c}\text { Nach } \\
\text { 60 Stunden }\end{array}$ \\
\hline Mit Essigsäure . . . . . . . & 7,6 & 29,2 & 37,1 & 38
\end{tabular}


Versuch 2 (Kalbsnieren).

Gesammtstickstoff 37,4 .

\begin{tabular}{|c|c|c|c|c|c|}
\hline . & . & $\begin{array}{l}\text { Vor der } \\
\text { Digestion }\end{array}$ & $\begin{array}{c}\text { Nach } \\
12 \text { Stunden }\end{array}$ & $\begin{array}{l}\text { Nach } \\
\text { 36 Stunden }\end{array}$ & $\begin{array}{l}\text { Nach } \\
60 \text { Stunden }\end{array}$ \\
\hline Mit Essigsäure $(0,25 \%)$ & . . & 6,4 & 26,6 & 29,8 & 33,4 \\
\hline Mit Milchsäure $(0,25 \%)$ & . . & - & 21,9 & - & - \\
\hline Mit $\mathrm{MgO} \cdot \cdot \cdot \cdot \cdot$ & $\cdot \cdot$ & - & 8,0 & 8,8 & 9,3 \\
\hline
\end{tabular}

Eine gekochte Probe ergab, sofort untersucht, die Ziffer 7, und mit Essigsäure 36 Stunden digerirt, 7,7. Eine mit Essigsäure und Fibrin (10 ccm. Presssaft $+.2 \mathrm{~g}$ feuchtes Fibrin) 60 Stunden lang digerirte Probe ergab die Ziffer 57,6 und die Kontrollprobe ohne Fibrin 33,4 (siehe Tabelle). Mit Magnesia und Fibrin wurde die Zahl 9,4 erhalten (Kontrollprobe ohne Fibrin 9,3).

In diesem Versuch wurde auch mit Phosphorwolframsäure gefällt. Der Stickstoffgehalt des Filtrats entsprach vor der Digestion 5,1 ccm. Säure und nach 84 Stunden mit Essigsäure $22,2 \mathrm{ccm}$.

Versuch 3 (Pferdeniere).

Gesammtstickstoff $\mathbf{5 2}$.

\begin{tabular}{|c|c|c|c|c|}
\hline & & $\begin{array}{l}\text { Vor der } \\
\text { Digestion }\end{array}$ & $\begin{array}{l}\text { Nach } \\
\text { 40 Stunden }\end{array}$ & $\begin{array}{c}\text { Nach } \\
6 \text { Tagen }\end{array}$ \\
\hline Mit Essigsäure & • • • • • • • & 8 & 31,5 & 39,4 \\
\hline Ohne Zusatz & . . . • • & - & 10,2 & 11,8 \\
\hline Mit $\mathrm{CaCO}_{3}$ & ・・・・・ & - & 9 & 10,8 \\
\hline
\end{tabular}

Mit MgO konnte in diesem Falle keine Bestimmung ausgeführt werden, weil das Ganze durch ausgefälltes Eiweiss in einen dicken Brei verwandelt worden war. Dasselbe war, wenn auch nicht in dem gleichen Grade, der Fall mit den Proben «ohne Zusatz» und mit $\mathrm{CaCO}_{3}$.

Versuch 4 (Hundsnieren).

Von 6 Nieren wurden nur $70 \mathrm{ccm}$. Presssaft erhalten, wesshalb $30 \mathrm{ccm}$. Wasser zugegeben wurde. 
Gesammtstickstoff des verdünnten. Safts 17.

\begin{tabular}{|c|c|c|c|}
\hline & $\begin{array}{l}\text { Vor der } \\
\text { Digestion }\end{array}$ & $\begin{array}{l}\text { Nach } \\
20 \text { Stunden }\end{array}$ & $\begin{array}{l}\text { Nach } \\
40 \text { Stunden }\end{array}$ \\
\hline Mit Essigsäure • • • • • • • & 5,4 & 14,5 & 15 \\
\hline Ohne Zugabe . . . . . . & - & 7,3 & 7,8 \\
\hline Mit $\mathrm{CaCO}_{3} \cdot \ldots \cdot \cdot \cdot \cdot$ & - & - & 6,0 \\
\hline Mit $\mathrm{MgO} \cdot$. $\cdot \cdot \cdot \cdot \cdot \cdot \cdot$ & - & 5,4 & 5,6 \\
\hline
\end{tabular}

Eine gekochte und 40 Stunden mit Essigsäure digerirte Probe ergab 6,8. Das Aufkochen scheint hier, sowie in den meisten Fällen, einen geringen Theil des Eiweisses in durch Gerbsäure nicht fällbare Form übergeführt zu haben.

Der Saft wurde auch mit Fibrin und Essigsäure digerirt (10 ccm. Saft $+2 \mathrm{~g}$ feuchtes Fibrin). Nach 12 Stunden war von dem Fibrin nichts mehr zu sehen, und nach 40 Stunden wurde für den nicht fällbaren Stickstoff die Zahl 16,8 erhalten. Da die Kontrollprobe ohne Fibrin die Ziffer 15 ergab (s. Tabelle), ist ersichtlich, dass das Fibrin wohl schnell aufgelöst wurde, aber dass nicht sehr viel davon in «Endprodukte» verwandelt worden war, wahrscheinlich in Folge der Verdünnung des Presssaftes.

Der Presssaft von Lymphdrüsen und von Nieren vermag nach den angeführten Versuchen in saurer Lösung sowohl sein eigenes Eiweiss, wie auch zugesetztes Fibrin zu verdauen; die Einwirkung ist schwächer oder fehlt ganz in neutraler und alkalischer Lösung. Da die Einwirkung nach Aufkochen ausbleibt, können wir folgern, dass die Lymphdrüsen und die Nieren, wie die Milz, eiweissverdauende Enzyme enthalten, die am stärksten in saurer Lösung wirken.

\section{Leber.}

Bekanntlich hat Salkowski ${ }^{1}$ ) zuerst in der Leber ein proteolytisches Enzym aufgefunden, das von Schwiening, ${ }^{2}$ ) Biondi, ${ }^{3}$ ) sowie neuerdings von Jacoby ${ }^{4}$ ) des Näheren studirt

1) Zeitschr. f. klin. Medic., 1890, Suppl.

2) Virchow's Archiv, Bd. 136, S. 444.

3) Virchow's Archiv, Bd. 144, S. 373.

4) Diese Zeitschr., Bd. XXX, S. 149. 
worden ișt. Aus den Versuchen von Schwiening geht hervor, dass die Gegenwart von Natriumcarbonat die Wirkung des Leberenzyms schwächt. Da wir sonst keine Angaben über die Bedeutung der Reaction für die Wirksamkeit des Enzyms haben finden können, haben wir hierüber folgende Versuche ausgeführt :

Versuch 1 (Rinderleber).

Gesammtstickstoff 61,5 .

\begin{tabular}{l|c|c|c|c}
\hline & $\begin{array}{c}\text { Vor der } \\
\text { Digestion }\end{array}$ & $\begin{array}{c}\text { Nach } \\
\text { 16 Stunden }\end{array}$ & $\begin{array}{c}\text { Nach } \\
\text { 40 Stunden }\end{array}$ & $\begin{array}{c}\text { Nach } \\
\text { 14 Tagen }\end{array}$ \\
\hline Mit Essigsäure . . . . . . & 7,8 & 22,8 & 30,8 & 41,2 \\
Ohne Zusatz.......... & - & 16 & 21,2 & - \\
Mit MgO . . . . . . . . & - & 8,8 & 9,9 & -
\end{tabular}

Mit Essigsäure und Fibrin wurde nach 14 Tagen die Zahl 53,7 erhalten. Kontrollprobe ohne Fibrin 41,2 (siehe Tabelle). In dem Lebersaft «ohne Zusatz», sowie in dem alkalischen wurde das Fibrin nicht merkbar aufgelöst und das Ganze bildete eine dicke Masse, die nicht analysirt werden konnte.

Versuch 2 (Hundsleber).

Gesammtstickstoff 62,5 .

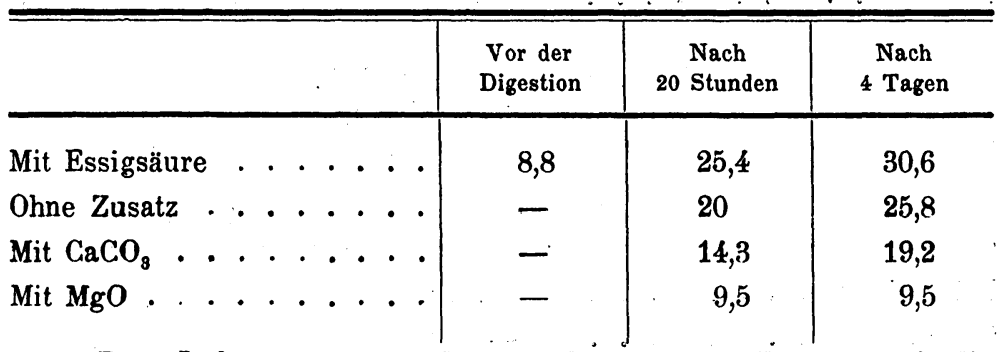

Das Leberenzym verhält sich also in Bezug auf die günstigste Reaction den von uns gefundenen Enzymen völlig analog.

\section{Skelettmuskeln.}

In den Skelettmuskeln ist von Salkowski und Schwiening ein Enzym nachgewiesen worden, das zwar sehr schwach ist, aber während sehr lang dauernder Einwirkung das Eiweiss 
bis zur Bildung von Leucin und Tyrosin spaltet. ${ }^{1}$ ) Um zu prüfen, ob die Reaction auf die Wirksamkeit dieses Enzyms irgend einen Einfluss ausübt, haben wir Muskelsaft derselben Prüfung wie andere Organe unterzogen.

Versuch 1 (Pferdemuskel). Gesammtstickstoff 23,1.

\begin{tabular}{|c|c|c|c|c|}
\hline & $\begin{array}{l}\text { Vor der } \\
\text { Digestion }\end{array}$ & $\begin{array}{c}\text { Nach } \\
2 \text { Tagen }\end{array}$ & $\begin{array}{l}\text { Nach } \\
\text { 6 Tagen }\end{array}$ & $\begin{array}{c}\text { Nach } \\
12 \text { Tagen }\end{array}$ \\
\hline Mit Essigsäure . • . • • . • & 8,5 & 8,8 & 9,6 & 9,6 \\
\hline Ohne Zusatz . . . . . • & - & $9, \tilde{0}$ & 10,2 & 11,4 \\
\hline Mit $\mathrm{CaCO}_{3} \cdot \cdot \cdot \cdot \cdot \cdot \cdot \cdot$ & - & 9,4 & 10 & 11,2 \\
\hline Mit $\mathrm{MgO}$. . . . . . . . . . & - & 8,8 & 9,4 & 9,9 \\
\hline
\end{tabular}

Versuch 2 (Pferdemuskel). Gesammtstickstoff 56,3 .

\begin{tabular}{|c|c|c|c|c|}
\hline & $\begin{array}{l}\text { Vor der } \\
\text { Digestion }\end{array}$ & $\begin{array}{l}\text { Nach } \\
2 \text { Tagen }\end{array}$ & $\begin{array}{l}\text { Nach } \\
5 \text { Tagen }\end{array}$ & $\begin{array}{l}\text { Nach } \\
1 \text { Monat }\end{array}$ \\
\hline Mit Essigsäure $\cdot$ • . • . • • & 17,8 & 30,6 & 33,8 & 45 \\
\hline Ohne Zusatz . . . . . . . & - & 33,4 & 36,5 & 51,4 \\
\hline Mit $\mathrm{CaCO}_{3}$. . . . . . & - & 31,2 & 37,1 & 53,4 \\
\hline Mit $\mathrm{MgO} \cdot \cdot \quad \cdot \cdot \cdot \cdot \cdot \cdot \cdot$ & - & 33,2 & 39,6 & 49,8 \\
\hline
\end{tabular}

Versuch 3 (Hundemuskel).

Gesammtstickstoff 44,1.

\begin{tabular}{|c|c|c|c|c|}
\hline & $\begin{array}{l}\text { Vor der } \\
\text { Digestion }\end{array}$ & $\begin{array}{l}\text { Nach } \\
4 \text { Tagen }\end{array}$ & $\begin{array}{c}\text { Nach } \\
12 \text { Tagen }\end{array}$ & $\begin{array}{c}\text { Nach } \\
26 \text { Tagen }\end{array}$ \\
\hline Mit Essigsäure . . . . . & 14,7 & 18 & 19,5 & 21,4 \\
\hline Ohne Zusatz . . . . . & - & 16,9 & 21 & 22,9 \\
\hline Mit $\mathrm{CaCO}_{3} \cdot \ldots \cdot \cdot \cdot \cdot$ & - & 16 & 17,8 & 18,4 \\
\hline Mit $\mathrm{MgO}$. . . . . . . & - & 15,3 & 15,3 & 16,6 \\
\hline
\end{tabular}

Eine Probe, die gekocht und ohne irgend eine Zugabe 12 Tage lang digerirt wurde, ergab die Zahl 15,7.

1) Zeitschr. f. klin. Medic., Bd. 17, Suppl., und Virchow's Archiv, Bd. 136, S. 444 . 
Das Muskelenzym erreicht somit nicht die Stärke der schon von uns abgehandelten Enzyme. Ein bestimmter Unterschied zwischen seiner Wirkung in saurer und alkalischer Lösung lässt sich nicht nachweisen.

\section{Herzmuskel.}

Da der Herzmuskel histologisch von den Skelettmuskeln verschieden ist, könnte ein in ihm möglicher Weise vorhandenes Enzym von dem der Skelettmuskeln verschieden sein. Folgende Versuche deuten auf ein Enzym hin, das in saurer Lösung etwas stärker wirkt, als in neutraler oder alkalischer. In dieser Beziehung scheint demnach das Herzenzym mit den übrigen von uns nachgewiesenen Enzymen übereinzustimmen.

Versuch 1 (Rinderherz).

Gesammtstickstoff 35,9 .

\begin{tabular}{l|c|c|c|c|c}
\hline & $\begin{array}{c}\text { Vor der } \\
\text { Digestion }\end{array}$ & $\begin{array}{c}\text { Nach } \\
\text { 16 Stunden }\end{array}$ & $\begin{array}{c}\text { Nach } \\
\text { 3 Tagen }\end{array}$ & $\begin{array}{c}\text { Nach } \\
\text { 5 Tagen }\end{array}$ & $\begin{array}{c}\text { Nach } \\
\text { 15 Tagen }\end{array}$ \\
\hline Mit Essigsäure . . & 9,6 & 13 & 17,9 & 19,4 & 22,6 \\
Ohne Zugabe... & - & 10,5 & 13,2 & 15 & 17,4 \\
Mit CaCO . . . . & - & 10,3 & 11,8 & 11,7 & 13,9 \\
Mit MgO ..... & - & 10,2 & 10,2 & 11 & 12,1
\end{tabular}

Versuch 2 (Hundeherz).

Gesammtstickstoff 37,6.

\begin{tabular}{l|c|c|c}
\hline & $\begin{array}{c}\text { Vor der } \\
\text { Digestion }\end{array}$ & $\begin{array}{c}\text { Nach } \\
\text { 2 Tagen }\end{array}$ & $\begin{array}{c}\text { Nach } \\
\text { 4 Tagen }\end{array}$ \\
\hline Mit Essigsäure . . . . . . & 10,8 & 16,2 & 19,4 \\
Ohne Zugabe . . . . . . . & - & - & 14,6 \\
Mit Mg0.......... & - & - & 12
\end{tabular}

Eine gekochte und 4 Tage mit Essigsäure digerirte Probe ergab die Zahl 10.

Ausser den schon erwähnten Organen haben wir noch andere Gewebe der Prüfung unterworfen, z. B. Milchdrüsen 
und Speicheldrüsen vom Rind. In den meisten Fällen haben wir eine unbedeutende Zunahme des durch Gerbsäure nicht fällbaren Stickstoffs beobachtet, und zwar war diese Zunahme am deutlichsten in mit Essigsäure versetzter Lösung.

Schliesslich sei noch erwähnt, dass wir auch versucht haben, zu eruiren, ob das Blut möglicher Weise ein proteolytisches Enzym enthalte. Im Blutplasma von Pferd und Rind haben wir mit'der angewandten Methode keine Spur von einem derartigen Enzym finden können, aber im Presssaft, bereitet von gequetschten Blutkörperchen, findet sich möglicher Weise ein sehr schwaches Enzym. Ob dieses von den weissen oder von den rothen Blutkörperchen herrührt, steht noch dahin.

Die bis jetzt von uns gewonnenen Resultate können folgendermassen zusammengefasst werden:

Bei allen von uns untersuchten Thierarten enthalten die Milz, die Lymphdrüsen, die Nieren und die Leber proteolytische Enzyme, welche ihre stärkste Wirkung in saurer Lösung entfalten.

Die Skelettmuskeln besitzen auch ein proteolytisches Enzym, das indessen relativ schwach ist und keinen deutlichen Unterschied in Bezug auf die Wirkung in saurer, neutraler oder alkalischer Lösung darbietet. Ein im Herzmuskel gefundenes Enzym nähert sich in Bezug auf seine Wirkung den eben abgehandelten Organenzymen.

Weitere Untersuchungen über die von uns gefundenen Enzyme sind schon in Angriff genommen.

London, Jenner Institute of preventive Medicine, den 7. Mai 1901. 